Title of the paper: Exploring the meaning of a new assistive technology device for older individuals

Authors:

Astrid Gramstad ${ }^{1,2}$, Sissel Lisa Storli ${ }^{1}$, Torunn Hamran ${ }^{1,2}$

${ }^{1}$ Department of health and care sciences, faculty of health sciences, University of Troms $\varnothing$, Norway

${ }^{2}$ Centre for care research North Norway

Corresponding author:

Astrid Gramstad

Department of health and care sciences

Faculty of health science

University of Troms $\varnothing$

N-9037 Troms $\varnothing$,

Norway

Telephone: +47 77660621

E-mail: astrid.gramstad@uit.no

Word count for text only, excluding references, abstract, figure and tables: 4783

Word count for abstract: 199

Number of tables: 1

Keywords: user experience, community health care 


\section{Exploring the meaning of a new assistive technology device for older individuals}

\section{Abstract}

Researching the outcomes of assistive technology devices (ATDs) for older clients is important to facilitate clinical decision-making. However, to understand the outcomes associated with ATDs, one must investigate the users' experiences and acknowledge the user as an active participant in diverse social contexts.

Purpose: To enhance understanding of the users' perspective regarding ATDs, this study aimed to investigate the meaning of the ATD for older individuals still living in their home environment.

Method: To provide descriptions of ATD experiences, older individuals who received a new ATD to compensate for their challenges in moving around, assist in self-care or both were recruited for the study. Participants were interviewed twice, with a few months between interviews, about their experience in using their new ATD. The interview transcripts were analysed in a hermeneutical-phenomenological research approach.

Results: The analysis revealed three recurring themes associated with the description of ATD experiences: 'enabling performance and choice', 'transformation from requiring assistance to assisting others', and 'preparing for the future'.

Conclusion: The results show that ATDs are used to enhance competence, mastery, control, self-worth, hope, and preparedness. The ATD service delivery should be client-centred and the client should be acknowledged as an active participant in producing change.

Key words: user experience, community health care 
Implementing technological solutions to enable and encourage older individuals to age at home is desirable $[1,2]$. Providing ATDs is one of the many interventions used in the rehabilitation of older individuals and is promising as a cost-effective and constructive method for solving future health care challenges [3-7]. Therefore, the provision of ATDs to individuals in need is publicly funded in Norway, and the municipalities are responsible for every aspect of the ATD delivery process [8]. One important group of health care professionals who aid individuals in the ATD service delivery process are occupational therapists, who have also developed guidelines for evidence-based ATD service delivery [3]. According to the Norwegian National insurance administration [9], successful ATD service delivery occurs when the ATD enables the user to better manage everyday life activities or when the strain on formal or informal caregivers is eased.

It is important to research ATD outcomes to ensure a sensible expenditure of costs, enable health care professionals and their clients to make informed decisions, and continue improvement of services and systems [10]. Outcome research is concerned with verifying causality between interventions and observed changes, as well as improving understanding of these relationships [11]. Therefore, a central goal of ATD outcome research has been to detect and measure the effects of ATDs in users' lives and environments [11, 12].

There are several complicating factors associated with the research of ATD outcomes. It is difficult to isolate the effects of ATDs, as they are provided to individuals in diverse contexts, and there is an indefinite number of possible outcomes [12]. Furthermore, the needs of an individual (relating to functional decline or improvement) can change over time, altering the benefits provided by the ATD [13]. Differences in perspective between stakeholders on aspects of importance can add a level of complexity. In other words, older individuals may 
find devices helpful and use them frequently, but these devices could be assessed by health care professionals as unsafe or inappropriate for the users' needs [14]. More knowledge is needed on the complexity of ATD implementations, how users experience the process of using an ATD, and how the introduction of an ATD may affect their lives.

Outcome studies that aim to verify whether an ATD is causally responsible for observed changes seem to imply two underlying assumptions. First, the ATD is assumed to be the main factor in instituting a change. Second, the users' task is to apply the ATD in certain defined situations for it to be effective. Both of these assumptions signal a view of the user as a passive recipient and of the ATD as having intrinsic power to produce a change.

To challenge these assumptions, research on users' experiences with ATDs shows that their degree of use is not only related to their functionality but also to the meaning attached to them by older individuals [15]. Becoming accustomed to an ATD is a process in which the users' own perception of needs, as well as social and physical contexts, influence the experience [16]. The meaning attributed to ATDs is influenced by the users' perceived difficulties, perceived faith in being well-served by the device, and perception regarding whether it corresponds to or challenges their self-image [17]. The ATD is considered both an instrumental object and an object that bears symbolic meaning for the user. It has been suggested that further research on ATD outcomes should not be restricted to studying the frequency of ATD use [18]. Therefore, in investigations regarding the effects of ATDs, the key goal should be to evaluate the user's own experience in depth.

Several user-perspective studies support the notion that everyday life is complex and unique to the individual (19). In their efforts to manage everyday life, older individuals may use ATDs for tasks or purposes other than what they were prescribed for [20]. Using an ATD has 
also been found to influence all aspects of life, and the use of such devices is often difficult to accept by older users [21-23]. To enhance understanding of the meaning a new ATD holds for older individuals, the present study is guided by a theoretical perspective that acknowledges the complexity of everyday life and attempts to evaluate the influence of an ATD from the user's perspective. This perspective is in agreement with the idea that people must be understood as situated participants in social practices, as stated by the Danish psychologist and social theorist Ole Dreier [19].

Dreier's theory is partially a criticism towards the traditional way of studying the effects of a therapy, which acknowledges therapists' skills and the therapy sessions as the most important factors with which to produce change in the client. Dreier instead emphasised the clients' ability to absorb, consider, and make use of therapy as determinants of whether change can occur. Dreier wrote that 'the effect therapy is meant to produce is essentially a change in client agency, that is, in client activities and experiences (...) We need a broader consideration of client agency within and beyond sessions in the contexts of the clients' everyday lives' [19 p.11]. Furthermore, everyday life must be understood as diverse social contexts that are reproduced and changed by participants because 'the actions and possibilities of its members, the meaning of participating in it, and the lives persons live in a social context hang together' [19 p.24]. This concept of participation also stresses the importance of the other participants in influencing, changing, and limiting the participation of the individual in social contexts [19 p. 29-30].

However, to look 'into the world and grasp the person as a participant in this world' [19 p.40] is not sufficient to investigate the symbolic meanings individuals associate with their ATD. When investigating the meanings of ATDs, it is necessary to elucidate and explore the 
experiences of the individual. Therefore, a hermeneutical-phenomenological research approach, according to the Dutch-Canadian professor of education Max van Manen, was used in conjunction with Dreier's theory [24]. The hermeneutical-phenomenological research approach acknowledges humans as embodied, situated, and historical beings who experience the world from their concrete and temporal perspective [24]. In addition, this study is guided by both a methodological individualism and an interactionism perspective [25], i.e., attention is being directed towards both the meaning of the experiences of the participants and their participation with other people in a multitude of contexts. In this study, lived experiences are defined as the experiences we live through as well as the meaning, understanding, and sense we may have made of these experiences [24].

To enhance understanding of the users' perspective of an ATD, this study aimed to investigate the meaning of ATDs that were used to compensate for difficulties involving mobility or performing self-care by older individuals living at home.

\section{Method}

This study involved two qualitative in-depth interviews with each participant. The first interview was conducted shortly after the ATD was received, and the second interview occurred a few months later. Interview guides with open-ended questions were developed for each of the two interviews, and the questions aimed to elicit a rich description of the participants' experiences during the process of receiving and living with the ATD.

The participants were recruited in two regions of Norway among individuals living at home aged >67 years who had applied for an ATD to compensate for difficulties with mobility, performing self-care, or both. To recruit participants, the first author approached occupational therapists working in ATD service delivery in the community and informed them of the 
project. The occupational therapists informed 11 potential participants of the project and gave them a letter containing information regarding the project, a consent form, and an addressed return envelope with prepaid postage. Eight individuals provided written consent and were included in this study. In cases in which the participant lived with a spouse, the spouse participated in the interviews if the participant requested the spouse to be present. These spouses were then informed of the study, and they provided their written consent to participate. In this way, four spouses were included. One participant could not be reached to make an appointment for the second interview. Therefore, this study is based on a total of 15 interviews. The characteristics of the participants and the ATDs are summarised in Table 1.

\section{TABLE 1 ABOUT HERE}

\section{Data collection}

The interviews were conducted in the participants' homes, with the exception of one that took place in the first author's office at the request of the participant. Field notes were written during and after the home visits to provide contextual detail for data interpretation. These notes included descriptions of situations in which the participant showed how they used the ATD. The interviews were conducted between November 2009 and January 2011 and lasted between 30 minutes and 2 hours. The first author taped and transcribed all interviews verbatim. The names of people and places were changed during the transcription process to maintain participant confidentiality.

The hermeneutical-phenomenological research approach implies that both the researcher and the participants have pre-understandings that influence what is perceived and are vital for developing both understandings and misunderstandings $[24,26]$. The first author, who 
conducted all the interviews, is an occupational therapist with experience working in community health care. Previous work experiences influenced what was observed and asked during the interviews, but the researcher attempted to be surprised by the experiences described by the participants [26]. A researcher is required to strive for openness and sensitivity towards the multitude and diversity of the participants' experiences as well as to ensure reflectivity regarding his/her own pre-understandings [24]. Therefore, the interviewer strived to let the experiences of the participants come forward in their own way [24]. The interview guides were adjusted throughout the data collection period according to new insights and questions that arose during the interviews.

The Regional Committee for Research Ethics and Norwegian Social Science Data Service approved the project.

\section{Data analysis}

As understanding has always already begun, analysis was conducted throughout the research process [26]. The interview transcripts were approached with the intention of identifying, understanding, and describing the meanings of the participants' experiences.

To elucidate themes or descriptions of important aspects of an experience, a highlighting analysis approach described by van Manen (24) was chosen. First, the analysis included reading the transcripts several times and listening carefully to the audiotapes to obtain a picture of the material both as a whole and for each of the participants [24]. The transcripts were then reread, and statements that related to the questions 'For what and where was the ATD used; what purpose did it serve; and how did it accomplish this objective?' were identified and highlighted [24]. van Manen defines a theme as an attempt to capture an 
experience but also as an abstraction and a simplification of the experience [24]. Through careful investigation of the highlighted statements, three recurring themes that described experiences of the ATDs were identified. These themes were then explored and probed by reflection, discussion, writing, and rewriting [24, 27]. The analysis process involved studying individual sentences from the transcripts and looking at the interview transcripts as a whole, and as understanding progressed, new questions and new insights were identified [26]. Reflections and evolving themes were written down and discussed among the researchers.

\section{Findings}

The analysis revealed the following three intertwining themes that described the experiences of a new ATD for older individuals: 'enabling performance and choice', 'transformation from requiring assistance to assisting others', and 'preparing for the future'.

The findings include statements from both the people who experienced difficulties and the spouses who participated in the interview. For clarifying purposes, members of these groups will be referred to as users and spouses, respectively. When quoting from interviews, participants will be presented by abbreviations signalling their status as users or spouses (U/S), the label of the participant, and a number indicating whether the quote was drawn from the first or the second interview with the participant (1/2).

\section{Enabling performance and choice}

The introduction of an ATD could expand the participants' scope of possibilities. Use of an ATD enabled performance, which meant that participation in meaningful activities was made possible. For one woman, the walker enabled her to visit the grave of a dear friend at a nearby 
churchyard alone. Another woman was able to do her own shopping and could therefore select the best vegetables available instead of having to accept the vegetables chosen by her family or the staff at the store. Having the opportunity to choose what to do and when to do it was deemed very important, and the ATD was considered central to achieving this independence.

Although the ATD provided the users with the ability to perform activities, it did not necessarily imply that the users made use of this new ability. One woman received a wheeled walker so that she could do her shopping and go for walks. After having it for three months, she noted that she had not used it very much. Still, she acknowledged that the opportunities it provided were important to her: 'For instance, if my husband is not at home, and I find out that I need to go to the mall or something [I can do it]' (UG2). Another participant received a lift chair to get out of chairs without the help of his wife. During the interview, he showed how he could adjust the chair to lie down, get up, and swing the chair around: 'I have this great view outside my window. I can just use this handle [he lifted the handle and turned the chair round]. If I want to look at the fiord, I can' (UJ1). At the last interview three months later, he said that he found a good position for the chair so that he could get up easily and still rest when sitting down without adjusting the chair. He acknowledged the ability to adjust his chair but concluded 'I experimented with driving the chair back and forth, and then I found that this position is the best. And now I can get up. It is very good. I like this chair a lot' (UJ2). Therefore, the scope of possibilities provided by introducing the ATD was acknowledged and appreciated, but the users did not necessarily make use of these possibilities in everyday life. 
In summary, the ATDs were important for the users in making it possible, or easier, to do what they needed or wanted to do. Having the ATD available enhanced feelings of competence and mastery in that the users were now enabled to perform activities that they were previously unable to perform. This feeling was also evident when the ATD was not actually used, as it nevertheless represented possibilities and freedom of choice. The users thought the ATD was a central factor in enabling performance and, therefore, having the freedom to participate in activities.

\section{Transformation from requiring assistance to assisting others}

The ATD could play a role in the transformation of the user from requiring assistance to being able to assist others. First, the users shared their thoughts regarding the ATD and its use by other people who may benefit from the ATD. One woman who received a lift chair said that 'I am going to recommend this chair to others that have trouble with their bodies' (UR2). The users related their experiences of using the device to others and also described how they allowed friends to try their ATD. A man stated that his neighbour had applied for the same ATD he had received, a cushion that made it easier to get out of chairs, after trying it out at his house: 'She was here and tried it out, and thought it was really good. And now she had called the occupational therapist and applied for one just like it' (UP2).

The users also provided advice regarding the ATD service delivery process to others to help their friends navigate the health care system. A woman who received a bidet stated: 'One of my friends was here and tried out the bidet. And her hip is really painful. And she said; How do you get about to apply for one of these? And I told her; go and talk to Lisa, the occupational therapist. She will help you out!'(UH2). 
Being able to perform activities independently or with less help from others motivated the use of the ATD. For users who relied on caregivers to perform everyday activities, the ATD was a means by which to ease the strain on these caregivers. Most users expressed that they needed less help from their spouse after they received and started to use the ATD. For example, one of the couples had different daily routines. The husband was used to getting up early, preferably at 5 o'clock in the morning, but his wife woke up later. After recovering from a femoral fracture, the husband needed help dressing, which meant that his wife had to interrupt her sleep to help him, or he had to sit undressed for hours waiting for her to wake up. His wife wanted to help him as she knew this was important to him, and she thought he would suffer if he had to stay in bed until late morning. After the husband received and started to use a reacher, he was able to get dressed on his own, and his wife could sleep as long as she needed. The husband described that 'It was my goal, to get dressed on my own. And it is still a goal to be able to manage everything on my own' (UP1).

The ATD allowed the user to stop requiring assistance and begin assisting others by giving guidance and tips to those in similar situations and by easing the strain on caregivers. Therefore, the ATD could be a mechanism for enhancing self-worth.

\section{Preparing for the future}

In reflecting on the use of their ATD, the users shared thoughts of their future, which they expected to entail increasing difficulties in managing their everyday life. The ATD provided a means by which to prepare for this future in two ways, namely, by representing a tool to counter or staunch future difficulties in performing activities and by symbolising hope for better days to come. Even when the ATD was not used, it was meaningful for the participants as a precaution and insurance that they could still endure if their function deteriorated. One 
woman noted that although she did not depend on her lift-chair to get up at the present time, she stated 'I reckon, with my upcoming surgery, I will be more restricted, and then I must use it' (UR2).

The participants used the ATD as a precaution as well as a way of maintaining a fragile and perhaps transitory balance in managing everyday life. One man stated that he did not use some of the ATDs he received but noted 'I got them. They can sit there for a while still, just in case I should need it. One does not know' (UP2). He said that during the rehabilitation of a previous femoral fracture, he received several ATDs, but as he improved, he returned these items. His wife stated: 'We were too quick on returning [the ATDs]. We thought that he had recovered so well. But... it did not last that long' (SO2). His functional limitations increased, and after he had struggled to manage everyday life for some time, they contacted the occupational therapist to obtain the previously returned ATDs in addition to some new ATDs. The man stated that even if he had not used all of the devices he received this time, 'If my back gets any worse, I need to start using them' (UP2).

Even though a man noted that he did not want to use the wheeled walker he received during winter and the roads were icy, he stated: 'but when the sun and warm weather comes, you will see me on the road with that one [pointing to the wheeled walker]' (UD1). Another woman stated: 'My friends invited me to visit them, now that I have received my wheeled walker, and I told them that I will, when the road conditions improve' (UE1). The ATDs represented opportunities to participate in joyful events that the users had found difficult to participate in previously. The ATDs therefore facilitated positive anticipation towards the future, involving hope and expectations for better days to come. 
The ATD was related to expectations of future difficulties and possibilities and was thought of as a means by which to counter these difficulties and take advantage of possibilities, therefore strengthening the users' control and hope. Having the ATDs facilitated a sense of being prepared and well-equipped to manage an uncertain future. The ATDs also represented a means to participate in future positive events. The user did not have to be actively using the ATDs for them to embody this meaning.

\section{Discussion}

The aim of this study was to investigate the experience of older individuals using a new ATD that was provided to compensate for difficulties involving mobility or performing self-care. The results showed that meanings of the ATD did not depend on whether the ATD was actively used, and the term "using the ATD" should also include the more abstract use of the devices by users. The ATDs enabled performance and choice, aided in the transformation of requiring assistance to assisting others, and aided in preparations for the future. The ATD facilitated and strengthened competence, mastery, control, self-worth, hope, and preparedness in the users.

The results indicated that the older individual who receives an ATD should be viewed by health care personnel as an active participant who does not merely apply for an ATD to overcome defined occupational difficulties; rather, the ATD is used by the user in many ways and is perceived by the user as important and meaningful. This perception could be because the ATD compensates for disability but also supports and enhances competence, belonging, hope, and preparedness. According to Dreier's theory, personal changes can occur in three ways [19]. First, the person may discover and make use of existing opportunities and 
participate differently in an unchanging social practise. Second, personal change may occur from changed social praxis. Third, personal change may occur when the person contributes to changing a social practice [19]. However, the client's agency is a central factor in instigating and upholding personal change. Compensating for disability and enabling the performance of daily activities also includes being able to choose to perform meaningful activities and become empowered. Therefore, less observable changes observed when introducing an ATD should be regarded as significant by health care professionals, ATD users, and outcome researchers.

Previous studies have demonstrated ambivalent meanings associated with ATDs in older individuals; ATDs have been found to be symbols of old age, weakness, and fragility, as well as instrumental in facilitating the development of independence and well-being [15, 21, 23, 28]. This study showed that ATDs can be positive and health-promoting, adding to the users' self-worth and competence, rather than representing disability and loss. Interestingly, none of the participants emphasised the ATD as stigmatising. On the contrary, they showed their ATD to their friends and told them about it. Therefore, their friends with unmet ATD needs could also benefit from their knowledge and experiences. Users were able to assist others by sharing their experiences with their friends with unmet ATD needs and relieving their caregivers. This ability contributed to the users' self-worth and competence. A consequence of disability is the cessation of doing, which is defined as 'the ability to engage in personally meaningful occupation' [29]. Experiencing difficulties in performing activities of everyday life can lead to a devaluation of oneself as a person and evoke feelings of being useless and worthless [29]. However, finding a way to help others can enhance perceptions of worth, competence, connections, and belonging, which can make life meaningful and enhance health [29]. The ATD held meaning for the participants because they were able to use it to help others, 
therefore adding to their experiences of feeling competent and valuable. Previous studies showed that friends and social support are important sources of information and influence decisions to apply for ATDs [30]. Adding to this knowledge, we found that the provider of such information may also benefit by feeling an increase in self-worth.

The results from this study confirm previous studies showing that spouses are profoundly influenced by the introduction of an ATD [31] and that the use of an ATD can benefit caregivers by decreasing their required efforts $[32,33]$. In addition to expanding participation for older individuals in their diverse contexts, the introduction of an ATD can also provide other people with new abilities with which to address their difficulties. Therefore, the introduction of an ATD is not just a personal affair but may have an effect on the participation of the user, the contexts in which the user participates, and other people in these contexts.

The ATD held a precautionary meaning for the users to guard against future functional decline and occupational performance difficulties, as well as provided hope for better times to come, such as another spring and warm summer. Being prepared for future challenges and possibilities may relate to feeling in control, which is associated with well-being and healthy aging [34]. Even when the ATD was not being actively used, the user believed it would be useful in the future, therefore adding to their perceived control and facilitating well-being.

As shown in this study and supported by previous studies, older individuals may not use the ATDs that are prescribed to them $[35,36]$. Non-use is deemed problematic because the patient does not receive the full benefit of the intervention [37]. However, the results of this study show that the ATD held meaning for the user even when the ATD was not used. 
Although the users in this study did not make full use of the possibilities provided by the ATD, the ATD still contributed to the users' perception of competence, self-worth, and preparedness. The ATDs played a role in the users' transformation from a disabled self to a competent self that was able to choose to participate in meaningful activities in diverse contexts and with other people [19, 29].

The frequency of ATD use as an important outcome measure may not correspond to the meaningfulness of the ATD as experienced by the user. Dreier's theory of people as situated participants in social practices proved useful in investigating the influences of ATDs in older individuals by adding the perspective of social contexts and stressing the importance of viewing the client as an active agent [19]. The hermeneutical phenomenological approach was useful in bringing forward and exploring meanings of ATDs for older individuals in these contexts [24]. The participants and their ATDs varied in this study, which may raise questions whether the results can be generalised. However, the aim of hermeneutical phenomenological research is to focus on the uniqueness and varieties of experiences and to produce descriptions that resonate with the readers' sense of lived life (24). The diversity of experiences, even within this small sample, underscores the uniqueness of each situation and emphasises the need for professionals working in ATD service delivery to acknowledge the uniqueness of their clients' situations.

ATDs have the potential to be a contributing factor in the users' perception of self-worth, competence, mastery, hope, and preparedness, as well as in the enhancement of performance and independence. ATDs do not have to be used actively to facilitate change within the user. The results of this study stress the importance of awareness of occupational therapists and other health care professionals working in ATD service delivery of the contexts in which the 
ATDs could be beneficial. This awareness requires the professional to be sensitive towards the meaning dimensions of the ATD as experienced by the user throughout the service delivery process. To enhance the full potential of ATDs, the service delivery should be clientcentred and include assessing and attuning to the variety of social contexts in which the ATD user participates, as well as acknowledging the client as an active participant in producing change. Further research on ATD outcomes should include the diverse social contexts of ATD use in the assessment of the impacts of introducing and using ATDs. More research is required to enhance our understanding of how the older individual experiences and uses a diversity of ATDs as well as how the use of ATDs influences users in a variety of contexts, such as their interaction with spouses and friends.

\section{Acknowledgements}

The results presented in this article are part of a $\mathrm{PhD}$ project funded by the Faculty of Health Sciences, University of Troms $\varnothing$.

\section{Declaration of interest}

The authors report no conflicts of interest. 
1. Norwegian Ministry of Health and Care Services, Norwegian official report 2011:11. Innovation in the care services. Oslo; 2011

2. World Health Organization and The World bank, World report on disability. Malta; 2011

3. NETF, Retningslinjer for kunnskapsbasert hjelpemiddelformidling (Guidelines for evidence based assistive technology device service delivery), 2011 [in Norwegian]

4. Daniels R, Metzelthin S, van Rossum E, de Witte L, van den Heuvel W. Interventions to prevent disability in frail community-dwelling older persons: an overview.

European Journal of Ageing 2010; 7(1):37-55.

5. Lansley P, McCreadie C, Tinker A. Can adapting the homes of older people and providing assistive technology pay its way? Age Ageing 2004;33(6):571-576.

6. Steultjens E, Dekker J, Bouter LM, Jellema S, Bakker EB, van den Ende CHM. Occupational therapy for community dwelling elderly people: a systematic review. Age Ageing 2004. 44(5).

7. Norwegian Ministry of Health and Care Services, Report no 29 to the Storting. The care of tomorrow [in Norwegian] Oslo; 2013.

8. Insurance act of 1997. Norwegian Ministry of Labour, Oslo.

9. The National Insurance Administration. The provision of assistive aids - part of a larger system. Information about the provision of assistive aids. The National Insurance Administration Oslo: 2003.

10. Soede T. With the start of a new year, a final editorial for Technology and Disability. Technol Disabil 2012;24(1):1-4.

11. Jutai JW, Fuhrer MJ, Demers L, Scherer MJ, DeRuyter F. Toward a taxonomy of assistive technology device outcomes. Am J Phys Med Rehabil 2005;84(4).

12. Fuhrer MJ, Jutai HW, Scherer MJ, DeRuyter F. A framework for the conceptual modelling of assistive technology device outcomes. Disabil Rehab 2003;25(22).

13. Demers L, Fuhrer MJ, Jutai JW, Scherer MJ, Perviewx I, DeRuyter F. Tracking mobility-related assistive technology in an outcomes study. Assist Technol 2008;20(2):73-83.

14. Aminzadeh F, Edwards N. Exploring seniors' views on the use of assistive devices in fall prevention. Public Health Nursing 1998;15(4):297-304.

15. Larsson Lund M, Nygård L. Incorporating or resisting assistive devices: different approaches to achieving a desired occupational self-image. OTJR: Occup, Particip Health 2003;23(2):67-75.

16. Skymne C, Dahlin-Ivanoff S, Claesson L, Eklund K. Getting used to assistive devices: Ambivalent experiences by frail elderly persons. Scand J Occup Ther 2012;19:194203.

17. Pape TLB, Kim J, Weiner B. The shaping of individual meanings assigned to assistive technology: a review of personal factors. Disabil Rehab 2002;24(1):5-20.

18. Auger C, Demers L, Gélinas I, Jutai J, Fuhrer MJ, DeRuyter F. Powered mobility for middle-aged and older adults. Systematic review of outcomes and appraisal of published evidence. Am J Phys Med Rehabil 2008;87(8).

19. Dreier O. Psychotherapy in everyday life. Cambridge: Cambridge University Press. XIV; 2008

20. Forchhammer HB. The woman who used her walking stick as a telephone: The use of utilities in praxis. In: Costall A, Dreier O, editors. Doing things with things. The design and use of everyday objects. England USA: Ashgate; 2006:131-46. 
21. Pettersson I, Appelros P, Ahlstrom G. Lifeworld perspectives utilizing assistive devices: individuals, lived experience following a stroke. Can J Occup Ther 2007;74(1):15-26.

22. Löfqvist C, Nygren C, Brandt $\AA$, Iwarsson S. Very old Swedish woman's experiences of mobility devices in everyday occupation: a longitudinal case study. Scand J Occup Ther 2009;16(3).

23. Häggblom-Kronlöf G, Sonn U. Use of assistive devices - a reality full of contradictions in elderly persons' everyday life. Disabil Rehab: Assist Technol 2007;2(6):335 - 345 .

24. van Manen M. Researching lived experience: human science for an action sensitive pedagogy. State university of New York press; 1990

25. Tjora A. Kvalitative forskningsmetoder i praksis. (Qualitative research methods in practice) Gyldendal akademisk Oslo; 2012,. [in Norwegian]

26. Gadamer HG. Truth and method. $2^{\text {nd }}$ ed. Continuum; London New York; 2006

27. van Manen M. Writing in the dark: phenomenological studies in interpretive inquiry. London, Ont: Althouse. II; 2002

28. Hedberg-Kristensson E, Ivanoff SD, Iwarsson S. Experiences among older persons using mobility devices. Disabil Rehab: Assist Technol 2007;2(1):15-22.

29. Hammell KW. Dimensions of meaning in the occupations of daily life. Can J Occup Ther 2004;71(5):296-305.

30. Gramstad A, Storli SL, Hamran T. 'Do I need it? Do I really need it?' Elderly peoples experiences of unmet assistive technology device needs. Disabil Rehab: Assist Technol 2013;8(4):287-93.

31. Pettersson I, Berndtsson I, Appelros P, Ahström G. Lifeworld perspectives on assistive devices: lived experiences of spouses of persons with stroke. Scand J Occup Ther 2005; 12(4):159-169.

32. Mortenson WB, Demers L, Fuhrer M, Jutai J, Lenker JA, DeReuter F. Effects of an assistive technology intervention on older adults with disabilities and their informal caregivers. An exploratory randomized controlled trial. Assist Technol 2013;92:297306.

33. Mortenson WB, Demers L, Fuhrer M, Jutai J, Lenker JA, DeRuyter F. How assistive technology use by individuals with disabilities impacts their caregiver. Assist Technol 2012;91:984-998.

34. Dulin PL, Hanson BL, King DK, Perceived control as a longitudinal moderator of late-life stressors on depressive symptoms. Aging Ment Health 2013;17(6):718-723.

35. Wessels R, Dijcks B, Soede M, Gelderblom GJ, De Witte L. Non-use of provided assistive technology devices, a literature overview. Technol Disabil 2003;15(4):231-8.

36. Kraskowsky LH, Finlayson M. Factors affecting older adults' use of adaptive equipment: review of the literature. Am J Occup Ther 2001; 55(3):303-310.

37. Wielandt T, Strong J. Compliance with prescribed adaptive equipment: a literature review. Br J Occup Ther 2000;63(2):65-75. 
Table 1 The participants and the devices they applied for

Age range 69-90

\begin{tabular}{llll}
\hline Pseudonym & $\begin{array}{l}\text { Reason to apply for an } \\
\text { ATD as told by the } \\
\text { participant }\end{array}$ & ATD received & Living with \\
\hline UD, male & Unsteady gait & $\begin{array}{l}\text { Wheeled walker } \\
\text { Shower chair }\end{array}$ & \\
\hline UE, female & Arthritis & Wheeled walker & (Spouse did \\
UG, female & Unsteady gait & Wheeled walker & participate in \\
& & & the study) \\
\hline UP, male & Complications after & $\begin{array}{l}\text { Cushion to get out of } \\
\text { chairs (sock puller, }\end{array}$ & SO \\
& femoral fracture & reacher, toilet seat stand) & \\
\hline$U$ UR, female & Arthritis & Lift chair & SK \\
\hline$U J$, male & Stroke & Lift chair & SL \\
\hline$U$ UH, female & Arthritis & Bidet & \\
\hline$U I$, female & Arthritis & Bidet & \\
\hline
\end{tabular}

Implications for rehabilitation

- Researching outcomes of assistive technology devices are complicated and should involve the user experience

- Assistive technology devices does not have to be used in concrete actions to involve meaning for the user

- Health care professionals should be sensitive towards the meaning dimensions of the assistive technology devices as experienced by the user throughout the service delivery process 